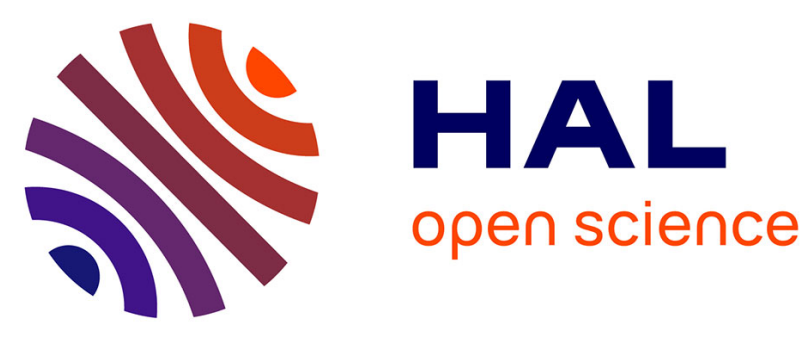

\title{
Predictive factors and prognostic value for status epilepticus in newborns
}

Zeynep Gokce-Samar, Karine Ostrowsky-Coste, Dominique Gauthier-Morel, Pascale Keo-Kosal, Julitta de Regnauld de Bellescize, Alexandra Montavont, Eleni Panagiotakaki, Olivier Claris, Alexis Arzimanoglou

\section{To cite this version:}

Zeynep Gokce-Samar, Karine Ostrowsky-Coste, Dominique Gauthier-Morel, Pascale Keo-Kosal, Julitta de Regnauld de Bellescize, et al.. Predictive factors and prognostic value for status epilepticus in newborns. European Journal of Paediatric Neurology, 2019, 23, pp.270 - 279. 10.1016/j.ejpn.2019.01.006 . hal-03485672

\section{HAL Id: hal-03485672 \\ https://hal.science/hal-03485672}

Submitted on 20 Dec 2021

HAL is a multi-disciplinary open access archive for the deposit and dissemination of scientific research documents, whether they are published or not. The documents may come from teaching and research institutions in France or abroad, or from public or private research centers.
L'archive ouverte pluridisciplinaire HAL, est destinée au dépôt et à la diffusion de documents scientifiques de niveau recherche, publiés ou non, émanant des établissements d'enseignement et de recherche français ou étrangers, des laboratoires publics ou privés.

\section{(ㄷ)(1) $\$$}

Distributed under a Creative Commons Attribution - NonCommercial| 4.0 International 


\section{Predictive factors and prognostic value for status epilepticus in newborns}

Zeynep GOKCE-SAMAR ${ }^{\text {a,*, Karine OSTROWSKY-COSTE }}{ }^{\text {a }}$, Dominique GAUTHIERMOREL $^{\text {a }}$, Pascale KEO-KOSAL ${ }^{\text {a }}$, Julitta DE REGNAULD DE BELLESCIZE ${ }^{\text {a }}$, Alexandra MONTAVONT a, Eleni PANAGIOTAKAKI ${ }^{\text {a }}$, Olivier CLARIS ${ }^{\mathrm{b}}$, Alexis ARZIMANOGLOU ${ }^{\mathrm{a}}$

${ }^{a}$ Epileptology, Sleep Disorders and Functional Pediatric Neurology, member of ERNEpiCARE; HFME, Hospices Civils de Lyon, 59 boulevard Pinel, Bron, France;

${ }^{\mathrm{b}}$ Neonatology Intensive Care Unit, HFME, Hospices Civils de Lyon, 59 boulevard Pinel, Bron, France

* Corresponding Author: Zeynep Gokce-Samar

Epileptology, Sleep Disorders and Functional Pediatric Neurology, member of ERNEpiCARE; HFME, Hospices Civils de Lyon 59 boulevard Pinel 69677, Bron, France e-mail address : zeynep.gokce-samar@chu-lyon.fr 
Keywords : Neonatal status epilepticus; neonatal isolated seizures; Hypoxic-ischemic encephalopathy; outcome; neurological examination; hypoglycemia.

Abbreviations : CI confidence interval, GA gestational age, HIE hypoxic-ischemic encephalopathy, NS not significant, OR odds ratio, SE status epilepticus, Video-EEG videoelectroencephalogram .

\section{INTRODUCTION}

Convulsions occur much more frequently in the neonatal period than at any other time in life. According to the literature, 8 to $43 \%$ of these seizures may evolve to status epilepticus (SE) $(1,2,3)$. Although neonatal convulsions have been widely studied $(4,5,6,7,8,9,10,11)$, the data on neonatal SE are scarce $(12,13,14,15,16)$.

Until recently the most common definition of SE was a seizure lasting more than 30 min or repeated seizures without return to preictal neurological baseline for more than $30 \mathrm{~min}$ $(7,13,17,18)$. ILAE Task force suggested of a shorter timeframe for SE because the prognosis of SE worsens with increasing duration (19).

In neonates, SE may be subtle and difficult to recognize and most authors agree that neonatal $\mathrm{SE}$ is often a negative prognostic factor $(2,7,17,20)$ for outcome. However, there are no data in the literature on the risk of SE in neonates, while others only have isolated seizures.

The aim of this study was to compare the characteristics of newborns who presented SE with those of newborns who had isolated seizures and to identify predictive factors for neonatal SE. The secondary objective was to study the prognostic factors for patient outcomes in newborns suffering either isolated seizures or SE.

\section{MATERIAL AND METHODS}

\section{Location and population}

Among the newborns admitted to the neonatal intensive and critical care units of the pediatric university hospital in Lyon, France (Hôpital Femme Mère Enfant, Bron), from January 1st 2010 to December $31^{\text {st }} 2014$, a total of 97 newborns presented abnormal movements suggestive of seizures (associated or not to an ictal discharge in the V-EEG) or presented only ictal discharges recorded on V-EEG without symptoms for very few of them . Ninety-one newborns suffered from neonatal seizures with 50 neonates who evolved to SE and 41 
neonates who presented only isolated seizures. Six newborns presented benign paroxystic movements.

For our study, neonatal status epilepticus was defined as continuous clinical or electrical seizure activity for more than $15 \mathrm{~min}$ or repeated seizures without return to preictal neurological baseline for more than $15 \mathrm{~min}$ (7). Isolated seizures were defined as one single seizure lasting less than $15 \mathrm{~min}$, or repeated seizures with complete recovery of consciousness between seizures.

\section{Inclusion criteria}

Our inclusion criteria were: a strongly suggestive clinical seizure and/or electrical seizure activity in a neonate with a gestational age (GA) of less than 44 weeks, requiring anticonvulsant therapy.

The seizures were classified as clonic, tonic, myoclonic and subtle according to Volpe's criteria (6). When patients presented several clinical ictal signs, only the dominant one was taken under consideration for statistical analysis.

\section{Video-EEG monitoring}

For all but one patient, video-EEG monitoring was initiated as soon as the equipment was available in preterm and full-term neonates showing signs of seizures $(5,6,8,21)$.

Only the first EEG recorded during the seizure or after the seizure if an EEG could not be recorded in the ictal phase, was retained for analysis.

The EEG was recorded at the newborn's bedside in the intensive or critical care unit using a mobile video-EEG machine, in the presence of a technician throughout the recording. The recording was made via 10 electrodes placed on the newborn's head according to the international 10-20 system, with in addition, muscle electrodes, a respiratory sensor, and ECG monitoring. Monitoring was continued until a full wakefulness, active sleep, quiet sleep cycle was completed, or if these three stages could not be clearly distinguished, the recording was prolonged for $60 \mathrm{~min}$ if possible.

The EEGs were analyzed using the software Micromed Systemplus by an experienced neurophysiologist. The EEGs were interpreted based on the newborn's age. The background 
activity was scored using Holmes and Lombroso's criterias (5,22,23), and classified (four classes) as normal, or having minor, moderate or severe abnormalities.

Seizure discharges on the EEG were considered significant if there was rhythmic activity for more than $10 \mathrm{~s}$, with a modified frequency and morphology and with a clear beginning and end $(22,23,24,25)$.

\section{Treatment protocol}

The patients were treated as follows $(1,26,27,28)$ : the first line of treatment was phenobarbital, initiated if seizures were lasting more than 5 minutes or were repeated, with a second dose if required. The second line of treatment was most often phenytoin, and the third, clonazepam. The fourth line of treatment was pyridoxine, which was administered earlier if there was a suspiscion of pyridoxine-dependent epilepsy. Intravenous levetiracetam was also administered as a fourth or fifth line of treatment. Prophylactic treatment following seizures was or not initiated after consultation with a neuropediatrician on a case-by-case basis. Our center started practicing therapeutic hypothermia only in 2014, for newborns suffering from HIE according to clinical, biological and electrographic criteria. Consequently we were able to include only one patient corresponding to the study period.

\section{Perinatal and neonatal data}

The following perinatal and neonatal parameters were recorded: GA in weeks, birth weight in grams, Apgar score at 1, 5 and $10 \mathrm{~min}$, biological data $(\mathrm{pH}$, blood sugar level, serum electrolyte levels), and need for resuscitation.

Obstetrical data and information about the mother (parity, age, medical history) were also recorded.

\section{Neonatal neurological examination}

The patients' neurological examinations, the first at birth and if possible before the onset of seizures, the second after the seizure episode just before leaving the neonatal unit, were classified as either normal, or moderately abnormal or severely abnormal, based on the Sarnat score and the Amiel-Tison method $(29,30,31,32)$. All patients received cranial ultrasound scans, completed if necessary by MRI.

\section{Neurological outcome}


Surviving patients received regular neurological follow-up examinations from a neonatologist at key stages of the Brunet-Lézine developmental scale, which were included in their medical record. Dual follow-up with a neuropediatrician was initiated for patients with neurological sequelae (epilepsy, developmental retardation). Outcomes were evaluated as positive or not one year after the seizure episode. Outcomes were considered negative in case of death, postnatal epilepsy, or severe sequelae (cerebral paralysis, blindness, deafness) and a favorable outcome was defined as normal neurologic development or mild muscle tone and reflexes abnormalities $(33,34,35,36)$.

\section{Statistical analysis}

Quantitative variables were described by their median and interquartile intervals. For the comparisons between groups (positive outcome or not, SE or not), the categorical variables were recoded as Boolean variables and compared using Fisher exact tests. Quantitative variables were compared using Mann-Whitney tests. These statistical analyses were carried out using $\mathrm{R}$, version 3.2.3. P-values of 0.05 were considered statistically significant, keeping in mind the exploratory nature of the analyses. The logistic regressions were performed using the glm function and the logit model in R. Exploratory data analysis was used to build a multivariate model: starting from an empty model (with no covariable), at each step, all the variables not included in the model were tested in multivariate analysis with those in the model and the most highly correlated one (with the lowest $\mathrm{p}$ value and $\mathrm{p}<0.05$ ) was added to the model. The variables in the new model with $p>0.05$ in multivariate analysis were then excluded, and so forth until no other variable could be added.

\section{RESULTS}

\section{General population characteristics}

Six newborns were excluded because they presented benign paroxysmal movements (tremorfor one newborn, sleep myoclonus for two newborns, unclassified non-specific isolated movements for three patients) with normal or difficult to interpret EEGs.

Our cohort consisted of 91 newborns, 50 in the SE group versus 41 in the isolated seizures group. Ten patients (11\%) were born at a GA of less than 29 weeks, 17 (19\%) at a GA between 30 and 36 weeks, and $64(70 \%)$ at or after term (GA $\geq 37$ weeks). The median GA was 38.5 weeks (36.1-40.1 weeks). The median birth weight of the cohort was $2900 \mathrm{~g}$ (2428$3555 \mathrm{~g})$. Thirty-three percent of the newborns were female and $67 \%$ were male. 
The main characteristics of the newborns by group (SE or isolated seizures) were as follows.

\subsection{Gender}

There were 34 males in the SE group (68\%) and 27 in the isolated seizures group (66\%, $\mathrm{p}=0.5)$.

\subsection{GA at birth}

The median GA in the SE group was 38 weeks (34.4-39.4 weeks) versus 38 weeks and 6 days in the isolated seizures group $(\mathrm{p}=1)$. Eight newborns in the SE group $(16 \%)$ were born before 29 weeks of GA versus 2 in the isolated seizures group (5\%, p=0.22), and 12 patients in the SE group (24\%) were born at a GA of 30-36 weeks versus 5 (12\%) in the isolated seizures group ( $\mathrm{p}=0.28$ ). Thirty of the neonates in the SE group (60\%) were born after 37 weeks of GA versus $34(83 \%)$ in the isolated seizures group $(\mathrm{p}=0.022)$.

\subsection{Birth weight}

The median birth weight in the SE group was $2750 \mathrm{~g}$ versus $3150 \mathrm{~g}$ in the isolated seizures group. Seven newborns in the SE group (14\%) had a birth weight lower than $1000 \mathrm{~g}$ versus one in the isolated seizures group $(\mathrm{p}=0.06)$. Five patients in the SE group (10\%) had a birth weight of between 1000 and $1499 \mathrm{~g}$ versus one in the isolated seizures group $(\mathrm{p}=0.1)$. Nine newborns in the SE group (18\%) weighed between 1500 and $2499 \mathrm{~g}$ at birth versus $3(7 \%)$ in the isolated seizures group ( $\mathrm{p}=0.227$ ), and 29 newborns in the SE group (58\%) had a birth weight above $2500 \mathrm{~g}$ versus $36(88 \%)$ in the isolated seizures group $(\mathrm{p}=0.00077)$.

\subsection{Obstetrical data}

The median maternal age in the SE group for 47 women (information missing for three patients) was 31 years versus 30 years in the isolated seizures group $(\mathrm{p}=0.22)$. Parity information was missing for one newborn in the SE group. Twenty-four women in this group (49\%) were primiparous versus 17 women in the isolated seizures group $(p=0.85)$.

Fifteen of the newborns in the SE group (30\%) were born by non-instrumental vaginal delivery versus $13(32 \%)$ in the isolated seizures group $(\mathrm{p}=0.95)$, and 30 were born by cesarean section $(60 \%)$ versus $17(41 \%)$ in the isolated seizures group $(\mathrm{p}=0.08)$.

\subsection{Apgar score}


The Apgar scores at birth in the SE group were as follows (data missing for two patients): at 1 min, between 0 and 3 for 24 newborns (50\%), 4-7 for 9 newborns (28\%), and 8-10 for 15 newborns (50\%). At $5 \mathrm{~min}$, between 0 and 3 for 9 newborns (19\%), between 4 and 7 for 5 newborns (10\%), and between 8 and 10 for 34 newborns (71\%). At $10 \mathrm{~min}$, between 0 and 3 for 8 newborns (17\%), between 4 and 7 for 11 newborns (23\%), and between 8 and 10 for 29 newborns (60\%). In comparison, the Apgar scores at birth in the isolated seizures group were as follows (data missing for one patient): at $1 \mathrm{~min}$, between 0 and 3 for 10 newborns $(25 \%$, $\mathrm{p}=0.081)$, between 4 and 7 for 10 newborns $(25 \%, \mathrm{p}=0.62)$, and between 8 and 10 for 20 newborns $(50 \%, \mathrm{p}=0.32)$. At $5 \mathrm{~min}$, between 0 and 3 for 3 newborns $(7 \%, \mathrm{p}=0.56)$, between 4 and 7 for 8 newborns (20\%, p=0.38), and between 8 and 10 for 20 newborns $(73 \%, p=0.97)$. At $10 \mathrm{~min}$, between 0 and 3 for 1 newborn (3\%, $=0.53)$, between 4 and 7 for 6 newborns $(15 \%, \mathrm{p}=0.34)$, and between 8 and 10 for 33 newborns $(82 \%, \mathrm{p}=0.41)$.

\subsection{Initial pathology data}

The blood tests at birth showed acidosis for 26 patients in the SE group (52\%), of which 17 (34\% of the SE group) had severe acidosis ( $\mathrm{pH}<7$ ), hypoglycemia for 15 newborns $(30 \%)$, and hyponatremia for two newborns (4\%). Initial pathology data from tests performed at birth or just before the seizure episode were missing for four patients in the isolated seizures group; compared with the results for those in the SE group, they showed, for the 37 remaining patients, acidosis for 14 newborns (40\%, p=0.44), including four with severe acidosis ( $11 \%$, $0.078)$, and hypoglycemia for two newborns $(\mathrm{p}=0.025)$.

\subsection{Resuscitation maneuvers}

Thirty-six newborns in the SE group (72\%) needed to be resuscitated at birth versus 18 (44\%) in the isolated seizures group $(\mathrm{p}=0.03)$.

\subsection{Initial neurological examination}

The initial neurological examination was abnormal for 34 newborns in the SE group (68\%), including 19 with a severe neurological presentation (38\% of the SE group) versus 18 newborns $(68 \%)$ in the isolated seizures group ( $\mathrm{p}=0.03)$, of which 2 had a severe neurological presentation $(5 \%, \mathrm{p}=0.014)$.

Table 1 summarizes the main characteristics at birth of the newborns in the SE and the isolated seizures group. 
Table 1. Main characteristics at birth of newborns in the status epilepticus and isolated seizures group.

\begin{tabular}{|c|c|c|c|}
\hline & $\begin{array}{l}\text { Status epilepticus } \\
\text { group }(n=50)\end{array}$ & $\begin{array}{l}\text { Isolated seizures } \\
\text { group }(n=41)\end{array}$ & $\mathrm{P}$ \\
\hline \multicolumn{4}{|l|}{ Neonatal data } \\
\hline Male sex & 34 & 27 & 0.5 \\
\hline Median gestational age (weeks) & 38 & $38+6$ & NS \\
\hline$<29$ weeks & 8 & 2 & 0.22 \\
\hline 29-36 weeks & 12 & 5 & 0.28 \\
\hline$>37$ weeks & 30 & 34 & 0.022 \\
\hline Median birth weight (g) & 2750 & 3150 & 0.016 \\
\hline$<1000 \mathrm{~g}$ & 7 & 1 & 0.06 \\
\hline $1000-1499 \mathrm{~g}$ & 5 & 1 & 0.1 \\
\hline $1500-2499 \mathrm{~g}$ & 9 & 3 & 0.227 \\
\hline$>2500 \mathrm{~g}$ & 29 & 36 & 0.00077 \\
\hline \multicolumn{4}{|l|}{ Obstetrical data } \\
\hline Median maternal age (years) & 31 & 30 & 0.22 \\
\hline Parity (primipara) & 24 & 17 & 0.85 \\
\hline Instrument-assisted delivery & 35 & 28 & 0.86 \\
\hline Including cesarean sections & 30 & 17 & 0.08 \\
\hline \multicolumn{4}{|l|}{ Apgar score } \\
\hline Apgar at $1 \min <4$ & 24 & 10 & 0.081 \\
\hline Apgar at $1 \mathrm{~min}, 4-6$ & 9 & 10 & 0.62 \\
\hline Apgar at $5 \min <4$ & 9 & 3 & 0.56 \\
\hline Apgar at $5 \mathrm{~min}, 4-6$ & 5 & 8 & 0.38 \\
\hline Apgar at $10 \min <4$ & 8 & 1 & 0.53 \\
\hline Apgar at $10 \mathrm{~min}, 4-6$ & 11 & 6 & 0.34 \\
\hline Resuscitation maneuvers & 36 & 18 & 0.03 \\
\hline \multicolumn{4}{|l|}{ Initial pathology results } \\
\hline Acidosis & 24 & 14 & 0.44 \\
\hline Hypoglycemia & 15 & 2 & 0.025 \\
\hline Abnormal initial neurological status & 34 & 18 & 0.03 \\
\hline Including severely abnormal & 19 & 2 & 0.0014 \\
\hline
\end{tabular}

Maternal age data missing for three newborns in the SE group

Parity information missing for one newborn in the SE group

Apgar scores missing for two newborns in the SE group and one newborn in the isolated seizures group

Pathology data missing for four newborns in the isolated seizures group 


\section{Underlying pathology}

The etiologies identified in the SE group were hypoxic-ischemic encephalopathy (HIE) for 22 out of 50 patients $(44 \%)$, an intraventricular hemorrhage in 8 cases $(16 \%)$, stroke for three newborns (6\%), a brain malformation (lissencephaly and hemimegalencephaly) for 2 newborns (4\%), a metabolic disorder for 4 newborns ((8\%) isolated hypoglycemia, fatty acid beta-oxidation defect, Leigh syndrome, pyridoxine-dependent convulsions), classified as "other etiologies" in 5 cases of infectious causes (10\% of the study group) and one iatrogenic cause (a brain tumor biopsy), and undetermined in 5 cases (10\%) .

In comparison, the etiologies in the isolated seizures group were HIE for 14 out of 41 patients (34\%, $\mathrm{p}=0.56)$, a brain hemorrhage in 9 cases $(22 \%, \mathrm{p}=0.60)$, stroke for three newborns $(\mathrm{p}=1)$, a brain malformation (dysplasic) for one newborn $(\mathrm{p}=1)$ a metabolic disorder for 2 newborns (hypoglycemia, peroxisomal disease, $\mathrm{p}=0.69$ ) . For the three remaining patients in the isolated seizures group with other etiologies $(\mathrm{p}=0.72)$, the cause was an infection in one case, Prozac withdrawal in the second case and one newborn had benign neonatal convulsions. The etiology was undetermined in 9 cases (10\%). Figure 1 illustrates the comparison between the main etiologies in the two groups.

Figure 1. Most frequent etiologies, with no significant difference between the two patient groups for any.

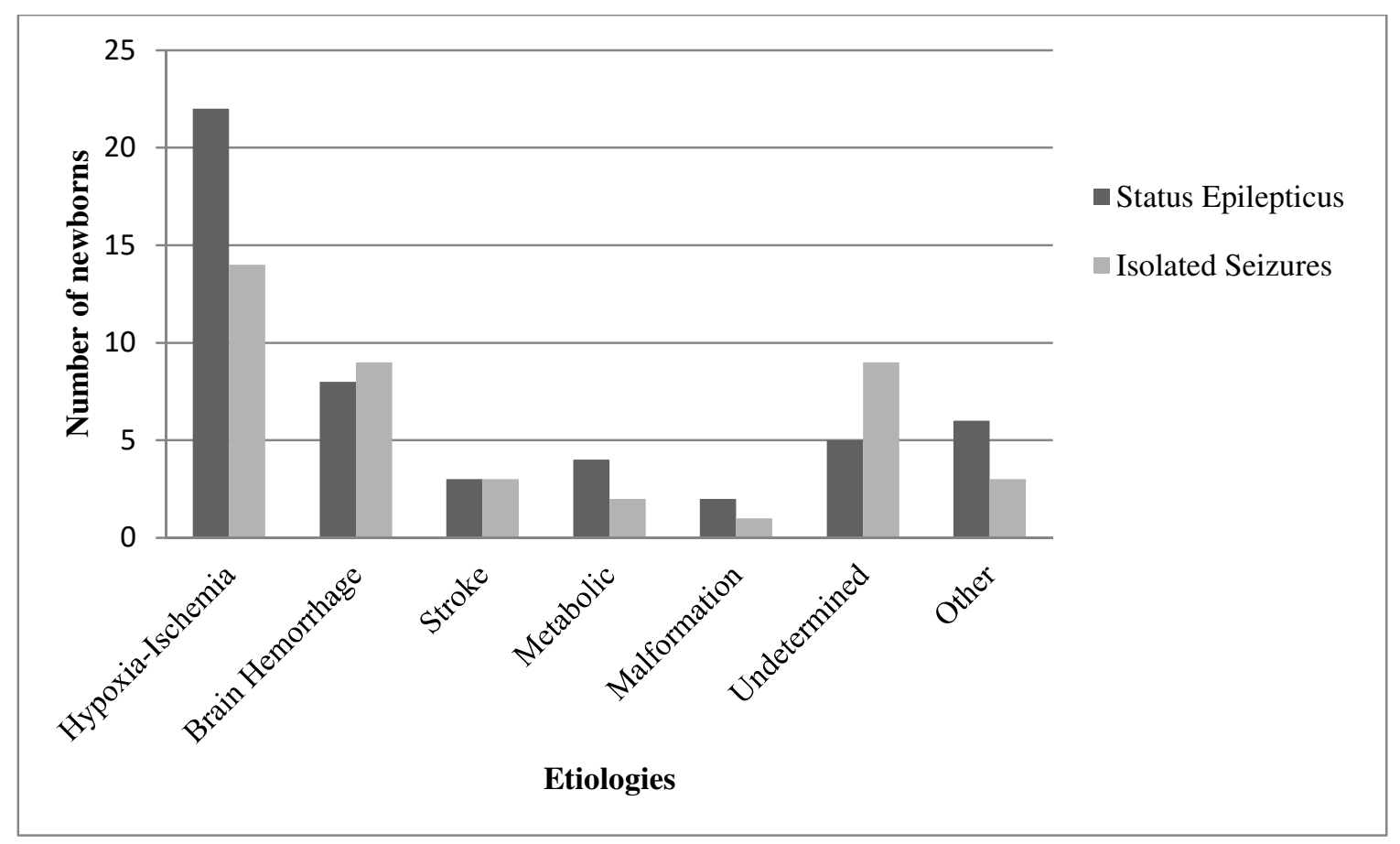




\section{Electroclinical characteristics of newborns in the status epilepticus versus isolated seizures group}

\subsection{Time of occurrence}

The seizure episode began in the first $24 \mathrm{~h}$ of life for 25 newborns in the SE group (50\%), between 24 and $48 \mathrm{~h}$ for 11 newborns (22\%), and after more than $48 \mathrm{~h}$ for 14 newborns (28\%). These events involved repeated seizures without return to consciousness for more than $15 \mathrm{~min}$, or even more than $30 \mathrm{~min}$ for almost patients; the seizure was continuous in only 4 cases. In comparison, 19 newborns in the isolated seizures group (46\%) experienced convulsions in the first $24 \mathrm{~h}$ of life ( $\mathrm{p}=0.86), 7$ newborns $(15 \%)$ between 24 and $48 \mathrm{~h}$ of life ( $\mathrm{p}=0.60)$, and 16 newborns (39\%) after $48 \mathrm{~h}$ of life, with 23 patients suffering more than one seizure $(\mathrm{p}=0.53)$.

\subsection{Clinical semiology}

The seizure episode was mainly clonic for 26 neonates in the SE group (52\%), subtle for 9 newborns (18\%), mainly tonic for 8 newborns (16\%), described as myoclonic for 3 newborns (6\%) and we recorded subclinical discharges for 4 newborns (8\%). Cardiorespiratory failure occurred in 16 cases (32\%). In comparison, the seizure episode was mainly clonic for 20 neonates in the isolated seizures group (49\%), subtle for 7 newborns (17\%), mainly tonic for 8 newborns (19\%), and described as myoclonic for 3 newborns (6\%). Cardiorespiratory failure occurred in $2 / 41$ cases $(5 \%, \mathrm{p}=0.007)$. Detailed description of seizure was missing for 3 neonates in the isolated seizures group.

\subsection{Video-EEG}

One patient in the SE group did not have EEG monitoring because he died rapidly. Seven newborns in the SE group and 29 newborns in the isolated seizures group had only interictal EEG. Seizures could be recorded for 42 patients in the SE group and for only 12 patients in the isolated seizures group. Background EEG activity was normal for one patient in the SE group (2\%) versus 13 patients $(32 \%)$ in the isolated seizures group $(\mathrm{p}=0.0009)$. Minor anomalies were present for 29 patients in the SE group (59\%) versus 22 patients (54\%) in the isolated seizures group $(\mathrm{p}=0.862)$. There were moderate anomalies for 11 patients $(22 \%)$ in the SE group versus 5 patients $(12 \%)$ in the isolated seizures group $(\mathrm{p}=0.414)$, and severe anomalies for 8 patients in the SE group (16\%) versus one patient (2\%) in the isolated seizures group $(\mathrm{p}=0.075)$. 
In SE group, the type of rhythm was a delta discharge in 32 neonates and a theta discharge in 10 neonates. The topography at onset was bilateral in 16 cases ( 3 bicentral, 5 bifrontocentral, 4 bitemporooccipital, bihemispherical 2 times and 2 times bioccipital), regional in 20 cases (6 times left frontocentral, 5 times centrotemporal left, 2 times temporooccipital left , 3 times right frontocentral, 2 right centrotemporal and 2 temporooccipital right), focal in 3 cases (vertex, right temporal, central left), hemispherical in 3 cases. We observed a contralateral propagation of the seizure for 15 patients, an ipsilateral propagation for 10 patients and a bilaterally propagation for 14 patients.

\subsection{Ictal pathology tests}

Ictal tests revealed acidosis for 13 newborns in the SE group (26\%) versus 6 newborns (15\%) in the isolated seizures group ( $\mathrm{p}=0.318$ ), hypoglycemia for 7 newborns in the SE group $(14 \%)$ versus one newborn $(2 \%)$ in the isolated seizures group $(\mathrm{p}=0.133)$, hyponatremia for 7 newborns (14\%) in the SE group versus one newborn in the isolated seizures group $(\mathrm{p}=0.133)$.

\subsection{Imaging}

All the newborns in both groups received a cranial ultrasound scan; 31 patients in the SE group and 27 in the isolated seizures group had an MRI. Seventeen newborns in the SE groups presented diffuse lesions involving both hemispheres versus 8 in the isolated seizures group $(\mathrm{p}=0.263)$.

\subsection{Treatment measures}

Two patients died before any antiepileptic drug was administered in the SE group. In the isolated seizures group, 9 patients didn't receive any antiepileptic-drug.

Phenobarbital was administered as a first line of treatment for 46 patients in the SE group (for two other patients, we do not know if they received phenobarbital before being transferred) versus 32 patients in the isolated seizures group $(\mathrm{p}=0.642)$. A second line of treatment was administered to 43 patients in the SE group (90\%) versus 3 patients (7\%) in the isolated seizures group $(\mathrm{p}<0.00002)$. No third or fourth-line treatment was administered to neonates in the isolated seizures group, whereas in the SE group, 15 patients $(30 \%, \mathrm{p}=0.004)$ had a third line treatment and 6 patients $(12 \%, \mathrm{p}=0.037)$ a fourth line treatment. Prophylactic therapy was then initiated for 18 patients in the SE group versus 9 patients in the isolated seizures group ( $\mathrm{p}=0.376$ ). One patient in the SE group underwent a therapeutic hypothermia. 


\subsection{Postictal neurological examination}

After the seizure episode, 11 patients in the SE group (22\%) had a normal clinical examination versus $31(76 \%)$ in the isolated seizures group $(\mathrm{p}=0.003)$. Thirty-nine patients in the SE group (78\%) had an abnormal clinical examination, including 28 (56\% of the SE group) with a severe neurological examination, versus 10 patients $(24 \%)$ in the isolated seizures group $(\mathrm{p}=0.005)$ including $6(15 \%$ of the isolated seizures group) with a severe neurological examination $(\mathrm{p}=0.006)$.

Table 2 summarizes the main electroclinical characteristics of newborns in the SE and isolated seizures groups.

Table 2. Electroclinical characteristics of the newborns in the status epilepticus group compared with those of the newborns in the isolated seizures group.

\begin{tabular}{|c|c|c|c|}
\hline & $\begin{array}{l}\text { Status epilepticus } \\
\text { group }(n=50)\end{array}$ & $\begin{array}{l}\text { Isolated seizures } \\
\text { group }(\mathrm{n}=41)\end{array}$ & $\mathrm{P}$ \\
\hline \multicolumn{4}{|l|}{ Seizure semiology } \\
\hline Clonic seizure & 26 & 20 & NS \\
\hline Tonic seizure & 8 & 8 & NS \\
\hline Myoclonic seizure & 3 & 3 & NS \\
\hline Subtle seizure & 9 & 7 & NS \\
\hline Subclinical discharges & 4 & 0 & 0.131 \\
\hline \multicolumn{4}{|l|}{ EEG data } \\
\hline activity & 1 & 13 & 0.0009 \\
\hline Minor anomalies & 29 & 22 & 0.862 \\
\hline Moderate anomalies & 11 & 5 & 0.414 \\
\hline Severe anomalies & 8 & 1 & 0.075 \\
\hline Cardiorespiratory failure & 16 & 2 & 0.007 \\
\hline \multicolumn{4}{|l|}{ Treatment } \\
\hline 2 lines & 43 & 3 & $<0.00002$ \\
\hline 3 lines & 15 & 0 & 0.0004 \\
\hline 4 lines & 6 & 0 & 0.037 \\
\hline Prophylaxis & 18 & 9 & 0.376 \\
\hline \multicolumn{4}{|c|}{ Postictal clinical examination } \\
\hline Normal & 11 & 31 & 0.003 \\
\hline Abnormal & 39 & 10 & 0.005 \\
\hline Including severely & 28 & 6 & 0.006 \\
\hline
\end{tabular}

Seizure semiology data missing for three newborns in isolated seizures group

EEG data missing for one newborn in SE group 


\section{Predictive factors for status epilepticus}

\subsection{In univariate analysis}

A GA greater than 37 weeks seemed to be a protective factor against SE (OR, $0.309(0.108-$ $0.803), \mathrm{p}=0.02)$.

A birth weight greater than $2500 \mathrm{~g}$ also seemed to be a protective factor against SE (OR, $0.149 ; 95 \%$ CI $(0.04-0.44), \mathrm{p}=0.0015)$.

Newborns who needed resuscitation had a higher risk of developing SE (OR, 2.700, 95\% CI (1.140-6.560), $\mathrm{p}=0.025)$.

Hypoglycemia at birth was a predictive factor for SE (OR, 8.360, 95\% CI (2.100-55.400), $\mathrm{p}=0.05)$. Acidosis on the other hand was not identified as a predictive factor (OR, 2.089, 95\% CI (0.901-4.980), p=0.9), even when it was severe (OR, 2.500, 95\% CI (0.946-7.200), $\mathrm{p}=0.073)$.

Abnormal neurological examination before the seizure episode was a predictive factor for the occurrence of SE (OR, 2.710, 95\% CI (1.170-6.510), $\mathrm{p}=0.022)$, particularly when described as severely abnormal (OR, $11.950,95 \% \mathrm{CI}(3.150-78.700), \mathrm{p}=0.0015)$.

An Apgar score of less than 7 at 10 min was also a predictive factor for the occurence of SE. (OR, 3.089, 95\% CI (1.180-8.880), $\mathrm{p}=0.027)$.

The seizures were more often described as clonic in the SE group than in the isolated seizures group (OR, 2.610, 95\% CI (1.110-6.420), p=0.038).

Table 3 recaps the main predictive factors for SE in univariate analysis. 
Table 3. Predictive factors for status epilepticus in univariate analysis.

\begin{tabular}{|c|c|c|c|}
\hline Variable & OR & $95 \% \mathrm{CI}$ & $\mathrm{P}$ \\
\hline \multicolumn{4}{|l|}{ Gestational age at birth } \\
\hline$>37$ weeks & 0.309 & $0.108-0.803$ & 0.02 \\
\hline \multicolumn{4}{|l|}{ Birth weight } \\
\hline$>2500 \mathrm{~g}$ & 0.149 & $0.040-0.440$ & 0.0015 \\
\hline \multicolumn{4}{|l|}{ Resuscitation at birth } \\
\hline Yes & 2.70 & $1.140-6.560$ & 0.025 \\
\hline \multicolumn{4}{|l|}{ Initial neurological examination } \\
\hline Abnormal & 2.710 & $1.170-6.510$ & 0.022 \\
\hline Including severely abnormal & 11.950 & $3.150-78.700$ & 0.0015 \\
\hline \multicolumn{4}{|l|}{ Hypoglycemia } \\
\hline Yes & 8.360 & $2.10-55.40$ & 0.05 \\
\hline \multicolumn{4}{|l|}{ Acidosis } \\
\hline Yes & 2.089 & $0.901-4.980$ & 0.9 \\
\hline \multicolumn{4}{|l|}{ Seizure } \\
\hline Clonic & 2.610 & $1.110-6.420$ & 0.038 \\
\hline \multicolumn{4}{|l|}{ Apgar at $1 \mathrm{~min}$} \\
\hline 0 to 3 & 2.330 & $0.979-5.770$ & 0.06 \\
\hline 4 to 7 & 2.200 & $0.929-5.330$ & 0.076 \\
\hline \multicolumn{4}{|l|}{ Apgar at $5 \mathrm{~min}$} \\
\hline 0 to 3 & 1.610 & $0.508-5.680$ & 0.43 \\
\hline 4 to 7 & 2.425 & $1.010-6.100$ & 0.053 \\
\hline \multicolumn{4}{|l|}{ Apgar at $10 \mathrm{~min}$} \\
\hline 0 to 3 & 1.800 & $0.520-7.200$ & 0.37 \\
\hline 4 to 7 & 3.089 & $1.180-8.880$ & 0.027 \\
\hline \multicolumn{4}{|l|}{ Parity } \\
\hline Primipara & 1.355 & $0.589-3.160$ & 0.48 \\
\hline \multicolumn{4}{|l|}{ Cesarean section } \\
\hline Yes & 2.118 & $0.940-4.980$ & 0.08 \\
\hline
\end{tabular}

The extent of the lesions identified by imaging was not identified as a significant predictive factor $(17 / 50$ vs $8 / 41$; OR, $1.74,95 \%$ CI (0.63-5.14), $\mathrm{p}=0.263)$, and neither were the etiologies or any of the other parameters considered.

\subsection{In multivariate analysis}

An abnormal initial neurological examination was the highest risk factor for SE, with an OR of 15.7 (95\% CI (3.810-109), $\mathrm{p}=0.00075)$. The other risk factor was hypoglycemia at birth (OR 6.820, 95\% CI (1.480-49.200), $\mathrm{p}=0.0243)$.

These two risk factors were mostly found in newborns with HIE. Indeed, the 18 newborns in the SE group with severely abnormal neurological examination results included 10 newborns 
who had HIE, and the 15 newborns in the SE group with hypoglycemia also included 10 newborns with HIE (such that roughly half of the newborns in the SE group had HIE). While there were only two cases of hypoglycemia in the isolated seizures group, both these newborns also had HIE.

A birth weight greater than $2500 \mathrm{~g}$ seemed to be a protective factor (OR $0.161,95 \% \mathrm{CI}$ $(0.039-0.551) . \mathrm{p}=0.0056)$.

Table 4 summarizes the factors identified as being independently predictive of SE in multivariate analysis.

Table 4. Independent predictive factors from status epilepticus

\begin{tabular}{llll}
\hline Variable & OR & $95 \% \mathrm{CI}$ & $\mathrm{P}$ \\
\hline $\begin{array}{l}\text { Birth weight } \\
\quad>2500 \mathrm{~g}\end{array}$ & 0.161 & $0.039-0.551$ & 0.0056 \\
$\begin{array}{l}\text { Initial neurological examination } \\
\quad \text { Severely abnormal }\end{array}$ & 15.700 & $3.810-109.100$ & 0.00075 \\
$\begin{array}{l}\text { Hypoglycemia } \\
\quad \text { Yes }\end{array}$ & & & \\
\hline
\end{tabular}

\section{Patient outcomes}

At one year follow-up across the two groups, 47 patients had a negative outcome and 37 patients had a positive outcome. Seven patients in total were lost to follow-up, five in the SE group and two in the isolated seizures group $(\mathrm{p}=0.46)$.

Only 7 patients in the SE group (14\%) had positive outcomes while 38 (76\%) had negative outcomes. In the isolated seizures group, 30 patients (73\%) had positive outcomes and 9 (22\%) patients had negative outcomes. Patient outcomes were significantly worse (death, epilepsy, severe sequelae) in the SE group than in the isolated seizures group (respectively 38 vs 9 patients, $\mathrm{p}=0.003$ ). Significantly more patients died in the SE group ( 24 newborns) than in the isolated seizures group ( 5 newborns, $\mathrm{p}=0.008$ ). However, the differences in terms of severe sequelae between the two groups is not significant (13 newborns in the SE group vs 4 in the isolated seizures group, $\mathrm{p}=0.11$ ), and likewise for the development of epilepsy (respectively 8 versus 3 newborns, $\mathrm{p}=0.34$ ). 
The occurrence of SE was a risk factor for a negative outcome only in univariate analysis. Thirty-eight of the 47 patients with negative outcomes had suffered SE, whereas just 7 patients who presented SE had favorable outcomes (OR, 4.228, 95\% CI (1.621-12.530), $\mathrm{p}=0.0016$ ). Suffering SE was not identified as a prognostic factor in multivariate analysis.

We compared for each group (status epilepticus and isolated seizures) newborns with positive and negative outcome in terms of neonatal, obstetrical and electroclinical data to identify predictive factors for outcomes in newborns suffering either isolated seizures or SE.

\section{Predictive factors for patient outcomes in the SE group}

\subsection{In univariate analysis}

Five $(71 \%)$ of the 7 newborns with positive outcome weighed more than $2500 \mathrm{~g}$ at birth compared with 21 (55\%) of 38 newborns who had a negative outcome (OR, 2.024, 95\% CI (0.382-15.400), $\mathrm{p}=0.43)$.

Six of the 7 newborns with favorable outcome in SE group (86\%), were born at more than 37 weeks of GA versus 20 of 38 newborns with negative outcome (53\%), (OR, 5.400, 95\% CI (0.814-107.000), $\mathrm{p}=0.13)$.

Five (71\%) of the 7 newborns with positive outcomes had a normal neurological examination after the seizure episode, versus 4 (11\%) of 38 newborns who had a negative outcome (OR 21.250, 95\% CI (3.440-191.000), $\mathrm{p}=0.002)$.

Background EEG activity was normal for only one patient for both the newborns in SE group.

\subsection{In multivariate analysis}

We don't found any predictive factors for outcome in multivariate analysis for patients in SE group.

\subsection{Predictive factors for patient outcomes in the isolated seizures group}

\subsection{In univariate analysis}


Twenty-nine (97\%) of the 30 newborns with positive outcome weighed more than $2500 \mathrm{~g}$ at birth compared with 6 (67\%) of 9 newborns who had a negative outcome (OR, 14.500, 95\% CI (1.570-323.000), $\mathrm{p}=0.031)$.

Twenty-seven of the 30 newborns with favorable outcome (90\%), were born at more than 37 weeks of GA versus 6 of 9 newborns with negative outcome (67\%), (OR, 4.500, 95\% CI (0.690-30.300), $\mathrm{p}=0.11)$.

Twenty-eight (93\%) of the 30 newborns with positive outcome had a normal neurological examination after the seizure episode, versus $2(22 \%)$ of 9 newborns who had a negative outcome (OR 48.999, 95\% CI (7.160-571.000), $\mathrm{p}=0.0003)$.

Background EEG activity was normal for eleven (37\%) of the newborns with positive outcomes but just for one (11\%) of the newborns with negative outcomes (OR, 4.632, 95\% CI (0.708-91.900), $\mathrm{p}=0.17)$.

\section{2. In multivariate analysis}

The only parameter significantly associated with patient outcome in the isolated seizures group was the postictal neurological examination before leaving the neonatal unit, with normal results being predictive of a positive outcome (OR, 48.999, 95\% CI (7.160-571.000), $\mathrm{p}=0.0003)$.

\section{DISCUSSION}

We report a series of 91 patients with neonatal seizures (50 with status epilepticus and 41 with isolated seizures), in which abnormal initial neurological status and hypoglycemia were found to be predictive factors for status epilepticus and post-ictal normal clinical examination was predictive of a good clinical outcome at 1 year follow up only for newborns with isolated seizures. A selection bias in our study could be the fact that all newborns at risk of seizures did not systematically have an EEG, particularly in the absence of other neurological signs. Most of our data are consistent with those in the literature, notably regarding electroclinical presentation, etiology, treatment measures, and patient outcomes. Our study most closely resembles that of Dreyfus-Brisac et al.'s (7), by choosing a primarily clinical definition of SE, considering both EEG-recorded seizures and those diagnosed by clinicians that had ended before the initiation of EEG monitoring either due to treatment or spontaneously. This 1981 study reported 121 cases of neonatal convulsions including 79 SE (7). This paradoxically high 
incidence of SE compared with isolated seizures is also observed in our study and probably reflects a selection bias toward more serious cases, which are more prevalent in or tend to be transferred to larger treatment centers. The predominant etiology in Dreyfus-Brisac et al.'s study was HIE, which is by far the most frequent cause in other studies for several decades (40-60\% of cases) $(38,39)$, and in our study HIE is occurring in $44 \%$ of newborns who suffered SE. The proportion of cases of undetermined etiology in our study, $10 \%$, is slightly lower than the 12-30\% range reported by Plouin et al. (12).

In Ramantani's review (40), there is converging evidence that etiology is the main predictor of outcome in neonates with seizures, but probably for statistical reasons, the underlying etiology of seizures is not found as a prognostic factor in our study.

Regarding the outcomes of the patients who presented SE, Dreyfus-Brisac et al. and other authors $(3,11,20)$ cite SE as an independent risk factor for a negative outcome, especially in premature newborns. In a recent study of neonatal SE, Pavlidis et al. (17) also found that all premature newborns who suffered SE had negative outcomes whereas $25 \%$ of those born at full term had positive outcomes. In our study, SE is only identified as a negative prognostic factor in univariate analysis.

The other usually described prognostic factors which are the background EEG activity, neurological examination, birth weight, and GA, were studied separately for patients in SE group and for patients in isolated seizures group. We found only in isolated seizures group an independent predictive factor for outcome : the postictal neurological examination, which importance has particularly been emphasized by Ortibus et al. (20), Clancy et Legido et al. (33), and Tekgul et al. (41). Even in the absence of any convulsive episode , Amiel-Tison et al. $(31,32)$ and Dubowitz et al. $(42,43)$ have in fact shown that there is a good correlation between the neurological examination at term for neonates, even those born prematurely, and their outcomes after one year. A normal neonatal neurological examination is thus often associated with a favorable outcome after 12 months; however, this relationship does not hold in reverse, abnormal neurological examinations lacking specificity.

As well as supporting existing results in the literature, our study provides new information by revealing two potentially controllable predictive factors for SE. 
The first is an initially severe neurological status. Newborns with an immediately worrying neurological status should therefore be monitored for at least $24 \mathrm{~h}$, since most episodes of SE occur in the first $24 \mathrm{~h}$ of life and rarely after $72 \mathrm{~h}(13,14,15,16)$.

When continuous EEG monitoring is not available, an alternative is amplitude-integrated EEG (aEEG), which is always available and can be interpreted by trained neonatologists. However, this investigation has to be interpreted with caution particularly in premature newborns whose activity is physiologically discontinuous (44). In Van Rooij's study of 311 at-risk full-term newborns monitored by aEEG (45), 18\% developed SE and the length of the episode was identified as a predictive of evolution toward HIE. However, short or very localized seizures, which are very frequent in newborns, are difficult to identify using aEEG (15). Furthermore, artifacts due to impedance errors and mispositioning are common. Amplitude-integrated EEG findings must therefore be validated systematically by standard video-EEG, which remains the technique "de reference" $(44,46,47)$.

The second predictive factor identified by this study is hypoglycemia. Low blood sugar levels are often measured following perinatal stress (48). Stress increases the energy requirements of the brain; maintaining homeostasis, in particular blood sugar levels, is therefore essential. The prognosis after hypoglycemia-induced seizures is often negative, with only $50 \%$ of patients surviving without sequelae. Gataullino et al.'s study (49) has shown that seizures associated with severe hypoglycemia, linked with hyperinsulinism or a congenital sugar-metabolism or beta-oxidation defect, evolve to SE in 32\% of cases, the SE occurring early (between 7 and 12 $\mathrm{h}$ of life), and are a particularly negative prognostic factor. Hypoglycemia can therefore aggravate seizures and lead to neuronal lesions $(1,26,49,50,51)$.

It is crucial to point out that in our study, almost half of the newborns with these risk factors had HIE. This study gives us insights on which newborns to monitor and what the available measures are to rapidly diagnose and treat neonatal convulsions, with the aim of improving patient outcomes, particularly for those with HIE.

\section{CONCLUSION}

This study has revealed two predictive factors for SE; the first is a severely abnormal initial neurological status and the second is hypoglycemia in the first few hours of life. These factors are present mostly in newborns with HIE and should lead to careful and close EEG monitoring and rapid seizure treatment of these newborns. Regarding the outcome, the only 
significant predictive factor is the postictal clinical examination in newborns with isolated seizures, normal results being associated with a positive outcome.

\section{CONFLICT OF INTEREST}

None.

\section{ACKNOWLEDGMENTS}

The translation of this article was supported by the Bibliothèque Scientifique de l'Internat de Lyon and the Hospices Civils de Lyon. We thank Skerdi Haviari for statistical analyses.

\section{REFERENCES}

1. Roubertie A, Masson F, de Villepin-Touzery A, Suau B, Barbanel G, Rideau A, et al Prise En Charge Des Crises Du Nouveau-Né. Arch de Pediatr. 2011;S56-64.

2. Scher MS. Neonatal seizures and brain damage. Pediatr Neurol. 2003 Nov;29(5):381-90.

3. Pisani F, Cerminara C, Fusco C, Sisti L. Neonatal status epilepticus vs recurrent neonatal seizures: clinical findings and outcome. Neurology. 2007;69:2177e85.

4. Mizrahi EM. Acute and chronic effects of seizures in the developing brain: lessons from clinical experience. Epilepsia. 1999;40 Suppl 1:S42-50; discussion S64-6.

5. Lombroso CT. Neonatal seizures: historic note and present controversies. Epilepsia. 1996;37:S5e13.

6. Volpe JJ. 1989. Neonatal Seizures: Current Concepts and Revised Classification. Pediatrics. 1989;84 (3): 422-28.

7. Dreyfus-Brisac C, Peschanski N, Radvanyl MF, Cukier-Hemeury F, Monod N. Convulsions du nouveau-ne. Aspects clinique, electrographique, etiopathogenique et prognostique. Rev EEG Neurophysiol. 1981;11:367-378.

8. Scher MS. Controversies regarding neonatal seizure recognition. Epileptic Disord. 2002 Jun;4(2):139-58.

9. Mizrahi EM, Kellaway P. Characterization and classification of neonatal seizures. Neurology. 1987 Dec;37(12):1837-44. 
10. Andre M, Matisse N, Vert P, Debruille C. Neonatal seizures--recent aspects. Neuropediatrics. 1988 Nov;19(4):201-7.

11. Yıldız EP, Tatlı B, Ekici B, Eraslan E, Aydınlı N, Calışkan M, et al. Evaluation of Etiologic and Prognostic Factors in Neonatal Convulsions. Pediatr Neurol. 2012;47 (3): 18692.

12. Plouin P., Sternberg B, Bour F, and Lerique A. Etats de Mal Neonataux D'etiologie Indeterminee. Revue d'Electroencéphalographie et de Neurophysiologie Clinique 1981;11 (3): $385-89$.

13. Mora EU, de Alba O-G, Garcia DV, Valdez JM. Neonatal status epilepticus I: clinical aspects. Clin Electroencephalogr. 1984;15:193e6.

14. Lawrence R, Inder T. Neonatal status epilepticus. Semin Pediatr Neurol. 2010;17:163e8.

15. Abend, NS., Wusthoff CJ. Neonatal Seizures and Status Epilepticus. J Clin Neurophysiol. 2012;29 (5): 441-48.

16. Wusthoff C J. Diagnosing Neonatal Seizures and Status Epilepticus. J Clin Neurophysiol. 2013;30 (2): 115-21.

17. Pavlidis E, Spagnoli C, Pelosi A, Mazzotta S, Pisani F. Neonatal status epilepticus: differences between preterm and term newborns. Eur J Paediatr Neurol. 2015 May;19(3):3149.

18. Prasad AN, Seshia SS. Status epilepticus in pediatric practice: neonate to adolescent. Adv Neurol. 2006;97:229e43

19. Trinka E, Cock H, Hesdorffer D, Rossetti AO, Scheffer IE, Shinnar S, et al. A Definition and Classification of Status Epilepticus--Report of the ILAE Task Force on Classification of Status Epilepticus. Epilepsia. 2015;56 (10): 1515-23.

20. Ortibus EL, Sum JM, Hahn JS. Predictive value of EEG for outcome and epilepsy following neonatal seizures. Electroencephalogr Clin Neurophysiol 1996;98:175e85.

21. Nguyen The Tich S. Clinical analysis of paroxysmal motor phenomena in the neonate. Arch Pediatr. 2011;S49-55. 
22. Holmes GL, Lombroso CT. Prognostic value of background patterns in the neonatal EEG. J Clin Neurophysiol. 1993;10:323-52.

23. Lombroso CT, Holmes GL. Value of the EEG in Neonatal Seizures. J Epilepsy. $1993 ; 6: 39-70$.

24. Scher MS, Hamid MY, Steppe DA, Beggarly ME, Painter MJ. Ictal and interictal electrographic seizure durations in preterm and term neonates. Epilepsia. 1993;34:284-8.

25. Clancy RR, Legido A. The exact ictal and interictal duration of electroencephalographic neonatal seizures. Epilepsia. 1987;28:537-41.

26. Kaminska A, Mourdie J, Barnerias C, Bahi-Buisson N, Plouin P, Huon C. [Management of neonatal seizures]. Arch Pediatr. 2007 Sep;14(9):1137-51.

27. Co JP, EliaM, Engel Jr J, Guerrini R, Mizrahi EM, Moshé SL, et al. Proposal of an algorithm for diagnosis and treatment of neonatal seizures in developing countries. Epilepsia. 2007;48:1158-64.

28. Slaughter LA., Patel AD, and. Slaughter JL. Pharmacological Treatment of Neonatal Seizures: A Systematic Review J Child Neurol. 2013;28 (3): 351-64.

29. Sarnat HB, Sarnat MS. Neonatal encephalopathy following fetal distress. A clinical and electroencephalographic study. Arch Neurol. 1976 ; 33 :696-705.

30. Amiel-Tison C. Le nouveau-né à terme. In : Amiel-Tison C., editor. Neurologie périnatale. Paris :Masson ;1999.p 107-26.

31. Amiel-Tison C, Grenier A, editors. Neurological assessment during the first year of life. Oxford: Oxford University Press; 1986.

32. Amiel-Tison, C. 1978. "A Method for Neurological Evaluation within the First Year of Life: Experience with Full-Term Newborn Infants with Birth Injury." Ciba Foundation Symposium, no. 59: 107-37.

33. Legido A, Clancy RR, Berman PH. Neurologic outcome after electroencephalographically proven neonatal seizures. Pediatrics. 1991;88:583-96.

34. Ronen GM, Buckley D, Penney S, Streiner DL. Long-term prognosis in children with neonatal seizures: a population-based study. Neurology. 2007 Nov 6;69(19):1816-22. 
35. Pisani F, Sisti L, Seri S. A scoring system for early prognostic assessment after neonatal seizures. Pediatrics. 2009;124:e580e587.

36. Watanabe K. Neurophysiological aspects of neonatal seizures. Brain Dev. 2014 May;36(5):363-71.

37. Monod N, Dreyfus-Brisac C, Sfaello Z. Depistage et pronostic de l'etat de mal neonatal d'apres l'etude electro-clinique de 150 cas. Arch Franc Pediatr 1969;25:1085-102.

38. Vasudevan C, Levene M. Epidemiology and aetiology of neonatal seizures. Semin Fetal Neonatal Med. 2013 Aug;18(4):185-91.

39.Arzimanoglou A, Gierrini R, Aicardi J. Neonatal seizures : Aicardi's epilepsy in children.3rd ed. Philadelphia : Lippincott Williams and Wilkins. 2004 :188-209.

40. Ramantani G. Neonatal epilepsy and underlying aetiology : to what extend do seizures and EEG abnormalites influence outcome ?. Epileptic Disord. 2013 ;15(4) :365-75.

41. Tekgul H, Gauvreau K, Soul J, et al. The current etiologic profile and neurodevelopmental outcome of seizures in term newborn infants. Pediatrics.2006;117: 1270-1280.

42. Dubowitz LMS, Dubowitz V, editors. The neurological assessment of the preterm and full-term infant. Clinics in developmental Medicine N/79. SIMP/Heinemann: London. Philadelphia: Lippincott; 1981.

43. Dubowitz LM, Dubowitz V, Palmer PG, Miller G, Fawer CL, Levene MI. Correlation of Neurologic Assessment in the Preterm Newborn Infant with Outcome at 1 Year. The Journal of Pediatrics 1984;105 (3): 452-56.

44. Bednarek N, Delebarre G, Saad S, Loron G, Mezguiche F, Morville P. 2008. Continuous two channel electroencephalography: description, applications, benefits and pitfalls . Arch Pediatr. 2008;15 (8): 1326-31.

45. van Rooij LG, de Vries LS, Handryastuti S, Hawani D, Groenendaal F, van Huffelen AC, et al. Neurodevelopmental outcome in term infants with status epilepticus detected with amplitude-integrated electroencephalography. Pediatrics 2007;120:e354e363.

46. Shellhaas RA., Clancy RR. Characterization of Neonatal Seizures by Conventional EEG and Single-Channel EEG. Clin Neurophysiol. 2007;118 (10): 2156-61. 
47. Pisani F, Pavlidis E. The role of electroencephalogram in neonatal seizure detection. Expert Rev Neurother. 2018 Feb;18(2):95-100. doi: 10.1080/14737175.2018.1413352.

48. Adamkin DH. Neonatal hypoglycemia. Semin Fetal Neonatal Med. 2016 ; 36-41.

49. Gataullina S, Delonlay P, Lemaire E, Boddaert N, Bulteau C, Soufflet C, Laín GA, Nabbout R, Chiron C, Dulac O. Seizures and Epilepsy in Hypoglycaemia Caused by Inborn Errors of Metabolism. Developmental Medicine and Child Neurology 2014;57 (2): 194-99.

50. Adamkin DH. Clinical report-postnatal glucose homeostasis in late preterm and term infants. Pediatrics ; $2011 ; 127$ :575-579.

51. Boylut N, Van Kempen A, Offringa M. Neurodevelopment after neonatal hypoglycemia : a systematic review and design of an optimal future study. Pediatrics. 2006 Jun;117(6):223143. 


\section{APPENDIX}

Definition of hypoglycemia in the newborn used in our neonatal unit.

In the first hours of life (before H4), hypoglycemia in the term newborn is defined as less than $1.8 \mathrm{mmol} / \mathrm{L}$ and less than $1.6 \mathrm{mmol} / \mathrm{L}$ in the premature newborn. Then from $\mathrm{H} 4$ to $\mathrm{H} 24$ the hypoglycemia threshold is $1.8 \mathrm{mmol} / \mathrm{L}$ for a premature newborn and $2 \mathrm{mmol} / \mathrm{L}$ for a term newborn.

After 24 hours, hypoglycemia is defined by a value below $2.4 \mathrm{mmol} / \mathrm{L}$.

In the status epilepticus group, 15 neonates had initial hypoglycemia : dextro low for 6 patients, at $1.5 \mathrm{mmol} / \mathrm{L}$ for 2 patients and $1.6 \mathrm{mmol} / \mathrm{L}$ for 2 other patients, a hypoglycemia is described initially without specifying the value for 5 patients.

In the isolated seizures group, 2 neonates had hypoglycemia at $0.6 \mathrm{mmol} / \mathrm{L}$ for one and 1.8 mmol / L for the other. 